\title{
Comportamentos de pais e professores para promoção da relação família e escola de pré- escolares incluídos
}

\author{
Ana Carolina Camargo Christovam*
}

Fabiana Cia**

\section{Resumo}

A literatura aponta evidências empíricas de que uma relação próxima entre a família e a escola pode ser efetiva para a construção de práticas de ensino adequadas e para a promoção do desenvolvimento da criança, principalmente no caso de crianças com necessidades educacionais especiais - NEE. O objetivo deste estudo foi descrever como 60 pais e 54 professores de alunos com NEE, matriculados na pré-escola, estabelecem a relação família-escola, considerando estratégias, frequência, atividades e situaçóes adotadas como promotoras da relação. Os dados foram coletados por meio de questionários e analisados por meio da análise de conteúdo. Os resultados indicam que os participantes estabelecem condiçóes para a relaçáo, no entanto, os pais não apresentam clareza da importância de suas açóes, levando ao baixo aproveitamento dessas situações, indicando a necessidade de investir na promoção do envolvimento efetivo, investindo em planos de ação, orientando participantes sobre o que e como fazer, aproveitando plenamente os benefícios da boa relação família-escola.

Palavras-chave: Envolvimento parental; Relação família-escola; Educação especial.

* Doutoranda em Educação Especial pela Universidade Federal de São Carlos, São Carlos, São Paulo, Brasil.

** Professora Adjunta do Departamento de Psicologia e do Programa de Pós-Graduação em Educação Especial da Universidade Federal de São Carlos, São Paulo, Brasil. 


\section{Behaviors of teachers and parents to promote family and school relationship of preschoolers included}

\section{Abstract}

The literature shows empirical evidence that a close relationship between parents and school can be effective for constructing appropriate teaching practices and to promote the necessary conditions for the development of the child, especially when dealing with children with special education needs. The aim of this study was to describe how 60 teachers and 54 parents of children with SEEs enrolled in preschool established the family-school relationship, considering strategies, frequency, activities and situations taken as promoters of the relationship. Data were collected through questionnaires and analyzed using content analysis. The data indicate that participants establish conditions for the relationship, however, parents do not show clarity of the importance of their actions, leading to low utilization of these situations, indicating need to invest in promoting the effective involvement, investing in action plans, orienting participants on what and how to do, taking full advantage of the benefits of good family-school relationship.

Keywords: Parental involvement; Family-School relationship; Special education.

\section{Introdução}

O incentivo à prática do envolvimento parental é um assunto relativamente recente na educação e tem se desenvolvido, sobretudo nos países norte-americanos, como resposta ao "No Child Left Behind Act (U.S. DEPARTMENT OF EDUCATION 2001)" ato normativo, implementado pelo governo americano que definiu seis grandes áreas de reforma na educação, dentre elas, o incentivo ao envolvimento parental como atividade capaz de promover alterações significativas no desempenho escolar dos alunos.

As pesquisas sobre o assunto têm aumentado consideravelmente e é possível identificar na literatura estudos que objetivam avaliar o impacto do envolvimento parental em suas mais diversas formas: estudos que buscam investigar se uma relação mais próxima impacta na formação do autoconceito (DUNN, 2004; JORGE, 1996), estudos que objetivam identificar impactos no desempenho acadêmico (HENDERSON, 1987; SMITH, 1998), estudos que verificam alteraçóes no desenvolvimento social das crianças (CONTE, 2001), dentre outros.

Segundo Smith (1998), embora muito se fale sobre o envolvimento parental, é possível identificar na literatura a falta de consenso sobre o que constituiria o envolvimento parental e quais as formas mais efetivas para promover o desenvolvimento da criança e a melhoria no desempenho acadêmico. Mesmo diante da falta de consenso, é comum encontrar a palavra "parceria" nas definiçôes de envolvimento. 
Epstein (1992) define o envolvimento parental como uma aliança formal e um acordo contratual entre a família e a escola. Para a autora, esta parceria se estabelece por meio de esferas sobrepostas de influência, ao incluir pais e professores como parceiros, que compartilham responsabilidades e interesses, trabalham com objetivos e direçôes comuns, com vistas ao desenvolvimento do aluno, partilhando dos benefícios do investimento conjunto.

Existem outras definiçôes para envolvimento parental, no entanto, para os fins desta pesquisa, o termo será utilizado para fazer referência à relação estabelecida entre a família e a escola, entendida como uma parceria efetiva, com potencial para impactar positivamente na escolaridade e no desenvolvimento de seus filhos.

A própria legislação brasileira, afirma a importância da participação da família na escolaridade dos filhos. A Lei de Diretrizes e Bases da Educação Nacional (BRASIL, 1996), por exemplo, afirma a importância de uma participação da família na vida escolar, agindo juntamente com o Estado para promover a educaçáo. Pensando especificamente no envolvimento parental de crianças com Necessidades Educacionais Especiais - NEE, Pereira (1996) afirma que uma relação próxima da escola traz benefícios positivos, não só para o aluno, mas para todos os envolvidos na relação. Os benefícios às famílias são: conhecer seus direitos e responsabilidades, conhecer informaçôes sobre a deficiência do filho, receber informaçôes de como pode ajudar no desenvolvimento da criança, conhecer os tipos de atividade que pode realizar em casa, aprender como ensinar novas competências às crianças, conhecer outros recursos que possam ajudar no desenvolvimento do deficiente. Já os profissionais se beneficiam, pois: podem conhecer as necessidades e recursos do ambiente familiar, conhecer necessidades e competências da criança não evidenciadas no ambiente escolar e podem programar atividades que possam ser desenvolvidas em casa pela família. E, finalmente, o aluno com NEE também se beneficia da relação quando: tem a possibilidade de socialização e envolvimento em ambientes seguros/potencializadores e a possibilidade de participação em serviços da comunidade antes não frequentados.

Segundo Pang (2008), envolver os pais na escolaridade dos filhos com deficiência pode ser muito positivo, pois, ao conhecer os recursos e necessidades das famílias, esses profissionais poderão reduzir o estresse que os familiares sofrem, proporcionando uma interaçáa colaborativa, ajudando neste processo de inclusão do aluno com NEE.

Considerando os importantes impactos de uma relação mais próxima entre a família e a escola, foram identificados inúmeros programas e propostas de instituiçóes para a promoção do envolvimento parental nas escolas americanas, porque embora existisse a informação da relevância de uma relação próxima entre a família e escola, as instituições não sabiam exatamente como proceder para efetivar esta parceria. $\mathrm{O}$ “Project Appleseed" (2010) é um exemplo destes programas, com grande impacto nos Estados Unidos, pode ser definido como um grupo sem fins lucrativos que busca consolidar parcerias entre pais e escola por meio de contrato de envolvimento na escolaridade dos filhos, instrumentalizando-os para isso. 
Ainda em relação aos programas, foram encontradas inúmeras propostas e programas em Portugal. A maioria destes programas era resultado de estudos, dissertaçóes e teses. Entre estes programas, destacam-se os estudos de Duarte (2001), que desenvolveu um programa de envolvimento parental na perspectiva da importância desta prática para a formação de adultos e de promoção da cidadania, e os estudos de Colaço (2007), que desenvolveu um programa de envolvimento parental para compreender a representação dos professores sobre a importância da relação escola-família. Estes trabalhos tiveram impacto positivo em relação a seus objetivos e reforçam a importância de desenvolvimento de programas com este propósito.

Seguindo a tendência de pesquisa internacional, pesquisadores brasileiros vêm realizando pesquisas sobre as relações família-escola, principalmente considerando alunos com NEE (BORGES; GUALDA; CIA, 2011; PAMPLIN, 2005; SALADINI; CIA; FANTINATO, 2011), ressaltando a importância do tema também em nossa realidade.

Em relação a programas específicos para promoção do envolvimento, Pamplin (2010) desenvolveu um programa para capacitar professores como agentes de promoçáo do envolvimento parental. O resultado de seu trabalho corrobora com os apontamentos da literatura, sobretudo, Portuguesa, que apontam a efetividade e a necessidade do desenvolvimento de programas para capacitar professores a implementar açóes que promovam o envolvimento parental.

Tendo em vista a importância do envolvimento parental e as evidências científicas de que uma relação mais próxima da escola é efetiva para a construção de práticas de ensino mais adequadas para a promoção das condições necessárias ao desenvolvimento da criança, salienta-se a importância da realização de pesquisas nessa direção, identificando elementos estabelecedores da relação escola-família, identificando como se dá o envolvimento desses pais na escolaridade dos filhos. Diante do exposto, o objetivo deste estudo foi descrever como pais e professores de crianças pré-escolares estabelecem a relação família-escola, considerando estratégias, frequência, atividades e situaçóes adotadas como promotoras da relação.

Esta pesquisa poderá complementar o conhecimento na área acerca da relação entre a escola e a família, isso porque o levantamento dos elementos envolvidos nessa relação poderá resultar em importantes indicativos para a implementação de práticas que promovam a relação entre as duas instâncias, diante do conhecimento das variáveis envolvidas no contexto. Diante do exposto, o objetivo deste estudo foi descrever como pais e professores de crianças pré-escolares estabelecem a relação família-escola, considerando estratégias, frequência, atividades e situaçóes adotadas como promotoras da relação.

\section{Método}

Foram participantes da pesquisa 60 pais e 54 professores de crianças com NEE (deficiência física, deficiência visual, deficiência auditiva, autismo, deficiência intelectual, síndrome de Down, atraso no desenvolvimento, diagnóstico não concluído, ou crianças que participavam do Atendimento Educacional Especializado - AEE, 
mesmo não apresentando diagnóstico), matriculadas na rede municipal de ensino de uma cidade do interior do estado de São Paulo.

Os professores participantes tinham em média 39 anos (variando entre 22 e 64 anos) e média de 13 anos de serviço na docência (com tempo de serviço variando entre um e 25 anos). Suas formaçôes variavam entre Pedagogia $(55,6 \%)$ e pedagogia com especializaçôes. Três professoras lecionavam para duas crianças com NEE. Os pais respondentes foram representados por nove homens (pais), 51 mulheres, sendo destas, 47 máes e quatro avós, com média de idade de 32 anos (variando entre 20 e 54 anos). O grau de escolaridade dos pais participantes variou prioritariamente entre Fundamental Completo (21,6\%) e Fundamental Incompleto (25\%).

A coleta de dados junto aos participantes ocorreu em uma sala reservada das unidades escolares participantes, localizadas em um município de médio porte do interior do estado de São Paulo. Para a realização da pesquisa, foi utilizado o seguinte instrumento: "Questionário Sobre a Relação Família e Escola no Processo de Inclusão - versão para pais e versão para professores", adaptado de Dias (1996), cujo objetivo é verificar a opiniáo dos respondentes quanto à relação entre a escola e a família de crianças com NEE.

Para identificar os possíveis participantes, foi enviado à Secretaria Municipal de Educação um ofício solicitando uma relação das escolas do município que tivessem alunos com NEE matriculados na educação infantil ${ }^{1}$. Após receber autorização, a pesquisadora contatou os responsáveis pelas Unidades Escolares - UEs e apresentou os objetivos da pesquisa e os procedimentos da coleta de dados. Uma vez obtida aprovação da direção da escola para realização da pesquisa, pais e professores foram contatados para verificar interesse em participar. Após os pais serem contatados e a coleta agendada, foi realizado contato com o professor da criança em questão e agendado encontro para realizaçáo dos procedimentos. O encontro com os participantes para coleta ocorreu nas creches e centros infantis, e seguiu o seguinte roteiro: apresentação da pesquisa, assinatura do Termo de Consentimento Livre e Esclarecido, explicação e aplicação do questionário.

Quanto à análise de dados, os questionários foram tabulados e analisados por meio de métodos descritivos e análise de conteúdo (COZBY, 2006; SAMPIERI; COLLADO; LUCIO, 2006).

\section{Resultados}

Os participantes foram indagados sobre a existência e a participação dos pais em comissóes para assuntos escolares/pedagógicos/sociais. Quando indagados da existência de conselhos/comissóes, 37\% dos professores alegaram existir apenas o Conselho de Escola, 18,5\% disseram existir Associaçáo de Pais e Mestres - APM, $24 \%$ afirmaram existência da APM e Conselho de Escola e, por fim, 20,3\% dos professores alegaram desconhecer a existência de conselhos/comissóes na escola. Os pais, por sua vez, quando inquiridos sobre a participação nas comissôes, 25\% alegaram participar apenas da APM, 15\% nấo participavam de nenhuma comissáo e 60\% desconheciam a existência de conselhos e comissóes na escola. 
Estes 25\% dos pais participantes alegaram participar apenas da associação de pais e mestres, por meio de contribuição financeira. Embora a escola ofereça várias comissóes para a participação dos pais, a adesão destes é pouco representativa. Segundo Paro (2001), os conselhos escolares são uma ferramenta muito útil para envolver os pais na vida escolar dos filhos, sobretudo dando poder na tomada de decisóes, e pode ser entendido como uma ferramenta de gestáo que articula os interesses da escola e da comunidade. No entanto, o que os professores dizem é que, embora a escola tenha os conselhos e associaçóes, os pais não são participativos, fazendo com que o conselho não alcance seu principal objetivo.

Segundo Anderson e Minke (2007), é papel do professor estar atento ao tipo de participaçấo exercida pelos pais. Muitas vezes, a forma utilizada pelo professor para chamar os pais à escola pode determinar a participação destes ou náo. Isso porque, muitas vezes, o chamado, além de pouco convidativo, não apresenta às famílias todos os seus objetivos e possíveis resultados, fazendo com que os pais não percebam aquilo como algo realmente importante. Quando os pais percebem que sua participação é algo desejado pelo professor e de valia para os filhos, estes frequentemente ultrapassam os obstáculos para estarem presentes e participativos.

Professores foram questionados sobre a existência de diferenças nas atitudes dos pais de crianças com NEE para com a escola, ou com o professor, em relação aos pais de crianças sem NEE. Trinta e sete por cento dos professores indicaram haver diferença no comportamento dos pais de aluno com NEE. No entanto, 62,9\% dos professores relataram que a atitude dos pais das crianças com NEE náo diferia da dos outros pais, conforme relato a seguir. Na Figura 1, apresenta-se a frequência com que os pais dos alunos com NEE vão à escola sem serem convocados pelos professores.

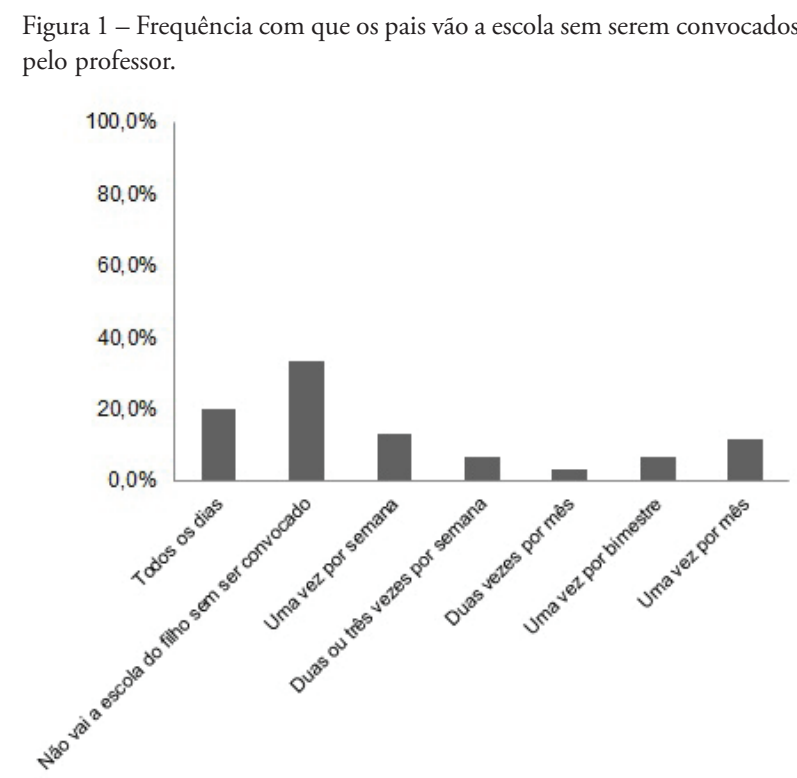


De acordo com a Figura 1, parte das respostas dos pais (33,3\%) indicou que estes náo iam a escola sem serem convocados pelo professor, seguido de $20 \%$ que indicaram ir à escola todos os dias. Conforme mencionado anteriormente, a maior parte dos professores alegou que os interesses dos pais de crianças com NEE eram os mesmos que os outros pais, como o comportamento, desenvolvimento e aprendizagem. Tal dado pode significar um possível desinteresse para com o processo educacional do filho, desconhecimento da importância da sua participação neste processo, ou, entâo, que todos os pais participam com a mesma frequência nas atividades acadêmicas dos filhos, independente dos filhos terem ou não NEE (corroborando com a diferença de resposta entre os pais $(33,3 \%)$ que alegaram não ir à escola sem convocação, e $20 \%$ que afirmaram ir todos os dias).

Esses dados diferem dos resultados encontrados por Dias (1996), uma vez que, em sua pesquisa, os professores relataram que os pais de alunos com NEE eram considerados, pelos professores, parceiros e apresentavam presença constante na vida escolar das crianças, contatando a escola com maior frequência. Esta diferença nos resultados pode ser explicada pela própria política portuguesa que apresenta uma forte tendência em envolver os pais na escolaridade dos filhos, investindo em açóes que promovam este tipo de atitude dos pais.

De acordo com a literatura, a participação da família na escola é muito importante, uma vez que esta poderá auxiliar o desenvolvimento da criança (BRASIL, 2006; PANIAGUA, 2004), porém, quando se trata de uma criança com NEE, este envolvimento é ainda mais crítico, pois a criança com essas características poderá enfrentar inúmeros desafios ao longo de sua trajetória, e a intervenção da família pode ser crucial nesse sentido. Segundo Dessen e Silva (2008), crianças com deficiência precisam que a família esteja atenta a seu desenvolvimento, promovendo suas competências e identificando seus avanços, acompanhando de perto o trabalho realizado pela escola.

As autoras afirmam ainda que os pais de crianças com deficiência devem, frequentemente, ser envolvidos em programas de intervenção, isso porque muitas vezes esses pais assumem papel integral de um co-terapeuta e implementam orientaçóes recebidas pelos profissionais da saúde e da educação, facilitando o processo de desenvolvimento dos filhos (DESSEN; SILVA, 2008). Esses dados ressaltam a importância de trazer os pais à escola e envolvê-los realmente na vida escolar, configurando-se como parceiros ativos na escolarização de seus filhos. Na Figura 2, apresenta-se a opiniâo de professore e pais sobre o tipo de estratégia utilizada pelo professor para comunicar-se com a família. 


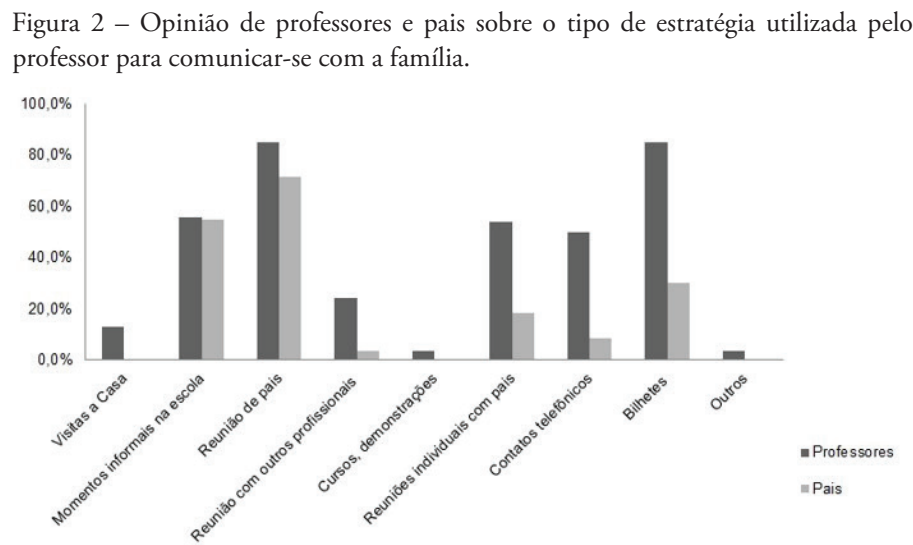

Como pode ser observado nos dados apresentados na Figura 2, professores e pais concordavam nas estratégias apontadas como mais adotadas para a comunicação com a família, como bilhetes (professores $85,1 \%$ e pais $30 \%$ ) e a reunião de pais (professores $81,1 \%$ e pais $71,67 \%$ ). Também foram apontados: momentos informais na escola (professores e pais 55\%), reunióes individuais (professores 53,7\% e pais $18,3 \%$ ) e contatos telefônicos (professores $50 \%$ e pais $8,3 \%$ ). Estes dados indicam que as escolas utilizavam diversas estratégias para comunicar-se com os pais. A principal ferramenta utilizada por eles foi o uso de bilhetes. O "caderno de recados" muito utilizado na educação infantil pode ser uma boa estratégia para comunicação, uma vez que é uma forma simples de informar o que se deseja e de realizar solicitaçôes.

É interessante notar que apenas 12,9\% dos professores indicaram realizar visitas à casa dos alunos, e que todos esses professores eram de uma mesma escola, escola esta que instituiu alguns projetos para melhorar a comunicação com a família, entre eles a ida do professor à casa, para participar os pais dos procedimentos a serem adotados pela escola ao longo do ano, chamando os pais a participar da escola, co-responsabilizando-os pela educação formal do filho. Este dado corrobora com estudos que apontam a necessidade de conhecer características do ambiente familiar de crianças com NEE (DIAS, 1996; FERREIRA; MARTURANO, 2002; PAMPLIN, 2010; PARREIRA; MARTURANO, 1999; PEREIRA, 1996) para efetivar práticas que podem promover uma relação adequada entre a casa e a família. Na Figura 3, mostra-se a opinião de professores e pais sobre as situaçóes que promovem o contato entre as duas instâncias (pais-professores e professores-pais). 


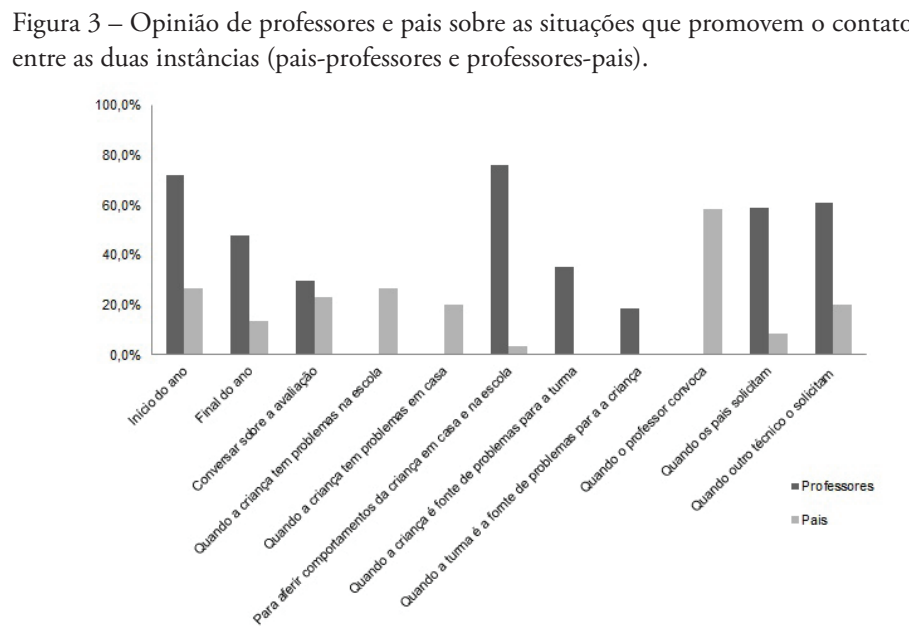

Os dados da Figura 3 são indicativos de que todo tipo de situação era aproveitada tanto por professores quanto para pais para dialogar com a outra parte. A maior parte dos professores indicou quase todos os tipos de situaçáo, dando destaque para: aferir comportamentos da criança em casa e na escola $(75,9 \%)$, início do ano $(72,2 \%)$, quando outro técnico solicita $(61,1 \%)$ e quando os pais solicitam $(59,26 \%)$. Já os pais indicaram: quando o professor convoca $(58,3 \%)$ e no início do ano $(26,6 \%)$.

Segundo os professores, a situação mais comum em que eles costumavam contatar os pais era para aferir comportamentos da criança em casa e na escola $(75,9 \%)$. Ao chamar os pais para aferir os comportamentos da criança em casa, o professor parece tentar estabelecer relaçóes para compreender o comportamento do aluno e estabelecer contingências possíveis para uma conduta adequada. Segundo López (2004), os pais são as melhores fontes para detectar problemas de comportamento.

Estes dados são sugestivos de que a relação estabelecida entre pais e professores provavelmente náo é entendida como um processo, que deve ser contínuo e permanecer ao longo do tempo, para que a participaçáo seja efetiva e acompanhe o desenvolvimento do aluno de modo geral. Enquanto a maior parte dos pais indica que conversa com o professor apenas quando convocados $(58,3 \%)$, professores fazem uso da reuniáo de pais como situaçáo para contato, mas este parece ir diminuindo progressivamente sendo menor apontado como situação de comunicação nas reunióes de final de ano, por exemplo (baixando de $75,9 \%$ para $48,1 \%$ no caso do professor ,e pais $26,6 \%$ para $13,3 \%$ ).

A reunião no início do ano poderá ser determinante do tipo de relação estabelecida entre a escola e a família, isso porque, dependendo do tipo de abordagem utilizada pelos professores, estes pais podem não se sentir bem-vindos e aceitos pela escola, e quando se tratam de alunos com NEE essa questáo é ainda mais complicada. Para que uma boa relação se estabeleça, é necessário que a escola se prepare para receber os pais criando estratégias para que o interesse dos mesmos pela instituição 
aumente (PANIAGUA; PALACIOS, 2007). Na Figura 4, são caracterizadas as opinióes de professores e pais sobre o tipo de informaçáo que os professores comunicavam aos pais.

Figura 4 - Opinião de professores e pais sobre o tipo de informaçáo que os professores comunicavam aos pais.

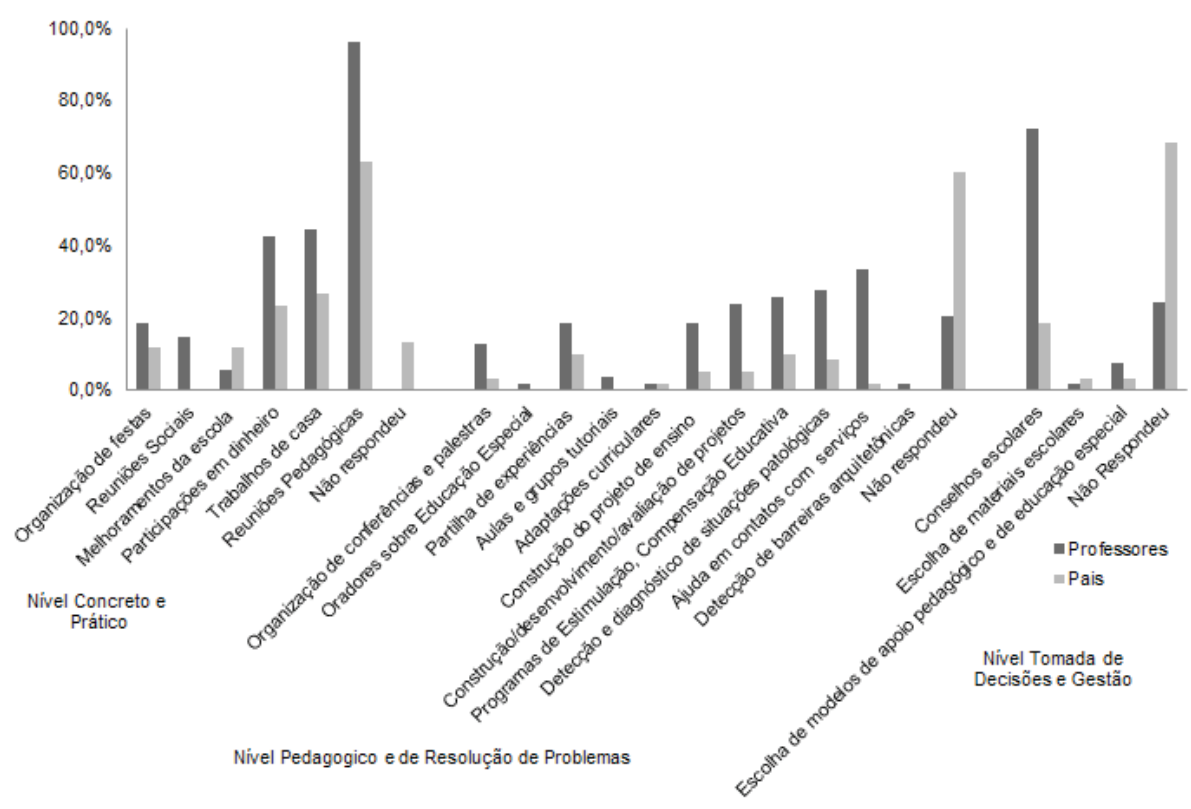

A partir dos dados da Figura 4, é possível verificar que professores e pais afirmaram que os primeiros comunicavam aos últimos todo tipo de informação: atitudes da criança em relação a outras crianças (professores $74 \%$ e pais $46,6 \%$ ), sucessos na aprendizagem escolar (professores $62,9 \%$ e pais $48,3 \%$ ), insucessos na aprendizagem (professores $61,1 \%$ e pais $23,3 \%$ ), atitudes da turma em relação à criança (professores $40,7 \%$ e pais $48,3 \%)$.

Esses dados indicam que a maioria dos professores relata aos pais atitudes da criança em relação ao restante da turma. Isso pode ser importante aos pais, pois fornece a estes informaçóes sobre o desenvolvimento da criança e também um comparativo em relação ao restante da turma, podendo servir como orientação aos pais sobre o que é esperado para aquela criança em relaçáo aos seus pares. Estes dados corroboram com Ferreira e Triches (2009), quando afirmam que, na medida em que os pais tomam conhecimento das etapas do desenvolvimento da criança, do que é esperado para sua idade, eles podem estimular o desenvolvimento das mesmas, apoiando os professores e auxiliando em casa realizando adaptações e intervençóes necessárias.

Professores e pais também apontaram que assuntos relacionados à aprendizagem escolar eram abordados no contato comunicativo entre eles, tanto em relaçáo ao sucesso quanto ao insucesso desses alunos. Paniagua e Palacios (2007) afirmam que é melhor que o professor aposte em enfatizar os sucessos dos alunos, isso por- 
que, muitas vezes, os professores têm hábito de contar aos pais apenas os fracassos e incapacidades do aluno, e essa informaçáo pode causar nos pais um sentimento de desânimo e culpa, afastando-os ainda mais da escola. Na Figura 5, são mostradas as opiniôes de professores e pais sobre o tipo de informação que os pais comunicavam aos professores.

Figura 5-Opiniáo de professores e pais sobre o tipo de informação que os pais comunicavam aos professores.

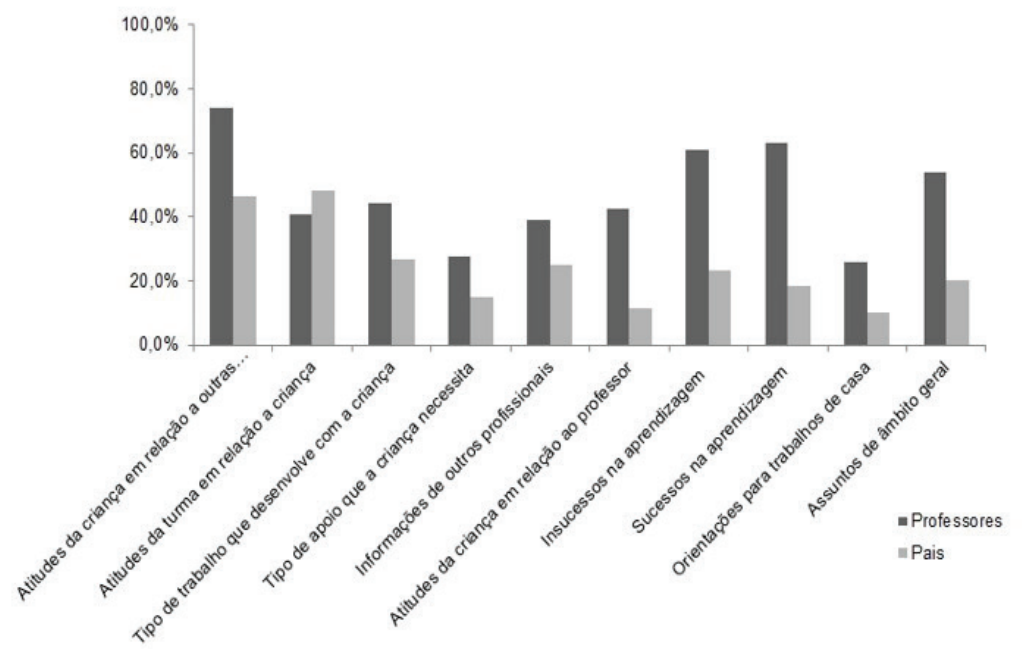

De acordo com a Figura 5, é possível verificar que, segundo professores e pais, as informaçóes que os pais frequentemente transmitiam aos professores eram: atitudes do filho em casa (professores $75,9 \%$ e pais $40 \%$ ), informaçóes transmitidas por outros profissionais (professores $57,4 \%$ e pais $41,6 \%$ ), ansiedades e medo em relação ao sucesso/insucesso do filho (professores $40,7 \%$ e pais $20 \%$ ) e situaçóes problemáticas na dinâmica da família (professores $27,7 \%$ e pais $20 \%$ ).

O fato de grande parte dos pais informar aos professores sobre os comportamentos das crianças em casa indica a tentativa dos pais de estabelecerem uma comunicação eficiente com a escola, informando ao professor aspectos que pensem ser relevantes para o desenvolvimento do aluno também no ambiente escolar.

Também citado pelos participantes foi a informação que os pais trazem de outros profissionais. Tais informaçôes poderão nortear as açóes da escola, e podem direcionar o trabalho do professor especialista, tornando as intervençóes mais precisas e com chance de ser mais eficiente.

Como se observa pelos dados, era comum também os pais informarem aos professores suas ansiedades e medos em relação à aprendizagem da criança e situaçóes problemáticas na dinâmica familiar. Esses dados apontam a necessidade de criação de grupos de apoio aos pais para enfrentarem as ansiedades relacionadas às dificuldades da criança com NEE, as experiências e também a necessidade do professor 
abordar estes pais com uma conduta mais reconfortante e encorajadora (ARANHA, 2004; GLAT, 2004;). Esses dados ressaltam, portanto, a importância do preparo do profissional para lidar com essas questóes. Para Pereira (1996), são importantes características do profissional que trabalha com crianças com NEE: capacidade de apoiar emocionalmente, partilhar informaçóes adequadamente e saber implementar programas adequadamente.

\section{Conclusão}

Os dados anteriormente apresentados são indicativos de como se comportavam pais e professores ao estabelecer a relação família-escola, considerando estratégias, frequência, atividades e situaçôes adotadas como promotoras da relação. Estes dados são sugestivos de que, embora exista uma comunicação entre as instâncias, muitas vezes as partes não percebem as situaçóes como potencialmente estabelecedoras da relação entre a família e a escola, de modo que, embora se relacionem, não aproveitem as situaçôes em toda sua dimensão e possibilidades, perdendo elementos que poderiam ser importantes na relação. Isso se deve, provavelmente, a uma falta de clareza e, portanto, necessidade de aumento de informaçóes adequadas do que seria e de como se estabelecer uma relaçáo produtiva entre a família e a escola e de que maneira ela poderia ser positiva ao desenvolvimento das crianças.

Para que o envolvimento parental ocorra de maneira funcional e que promova o desenvolvimento da criança como um todo, seria necessário investir em ações que promovessem um envolvimento efetivo e uma maior conscientizaçáo dos benefícios de uma relação parental próxima para todas as instâncias. Seria necessário investir em planos de ação, que orientassem os participantes como eles poderiam contribuir mais com o desenvolvimento da criança pré-escolar incluída.

\section{Referências}

ANDERSON, K. J.; MINKE, K. M. Parent involvement in education: Toward an understanding of parent's decision making. The Journal f Educational Research, v. 100, n. 5, p. 311-323, 2007.

ARANHA, M. S. F. Inclusáo social e municipalizaçáo. Novas Diretrizes da Educação Especial. São Paulo: Secretaria Estadual de Educação, 2004.

BORGES, L.; GUALDA, D. S.; CIA, F. O papel do professor na relação com as famílias de crianças pré escolares incluídas. In: VI Congresso Brasileiro multidisciplinar de Educação Especial. Anais do VI Congresso Brasileiro Multidisciplinar de Educação Especial, ano 2011. ABPEE: Londrina, 2011. p. 1249-1256.

BRASIL. Senado Federal. Lei de Diretrizes e Bases da Educaçáo Nacional. Brasília: 1996.

Ministério da Educação. Educação Infantil - Saberes e Práticas da inclusão: Introdução. Brasília: 2006

COLAÇO, M. M. I. A. A relação Escola-Família e o envolvimento dos pais: Representações de professores do $1^{\circ}$ Ciclo do Conselho de Rio Maior. Dissertação de Mestrado em Administração e Gestão Educacional. Universidade Aberta: Lisboa, 2007

CONTE, F. C. S. Promovendo a relação entre pais e filhos. In: M. DELITTI (Org.). Comportamento e cognição: A prática da análise do comportamento e da terapia cognitivo comportamental. Santo André: Esetec, 2001. p. $161-168$.

COZBY, P. C. Métodos de pesquisa em ciências do comportamento. 2 ed. São Paulo: Editora Atlas, 2006. p. 454. 
DESSEN, M. A.; SILVA, S. Famílias e crianças com deficiência: Em busca de estratégias para promoção do desenvolvimento familiar. In: BOLSANELLO, M. A. (Org.). Atençáo e estimulaçáo precoce. Curitiba: I Simpósio Nacional de Atenção e Estimulação Precoce, 2008. p. 39-58.

DIAS, J. C. A problemática da relaçáo família/escola e a criança com necessidades educativas especiais. Coleção Cadernos SNR, n. 11. Portugal: Instituto Jean Piaget, 1996. p. 158.

DUNN, J. Annotation: Children's relationships with their nonresident father. Journal Of Child Psychology and Psychiatry, v. 45, n. 4, p. 659-671, 2004

DUARTE, M. I. Formaçáo de adultos e cidadania: (Re)pensar as práticas de envolvimento parental na escola. Dissertação de Mestrado em Ciências de Educação. Universidade nova de Lisboa, 2001.

EPSTEIN, I. L. School and family partnerships: Leadership roles for school psychologists. In: CHRISTENSON, S. L.; CONOLEY, L. C. HomeSchool Collaboration: Enhancing Children 's Academic and Social Competence (pp. 499-515). Silver Spring: National Association of School Psychologists, 1992.

FERREIRA, M. C. T.; MATURANO, E. M. Ambiente familiar e os problemas de comportamento apresentados por crianças com baixo desempenho escolar. Psicologia: Reflexáo e Crítica, v. 15, n. 1, p. 35-44, 2002

FERREIRA, S. L. G.; TRICHES, M.A. O envolvimento parental nas instituições de educação infantil. Revista Pedagógica, Chapecó, v. 11, n. 22, p. 43-44, 2009.

GLAT, R. Uma família presente e participativa: O papel da família no desenvolvimento e inclusão social da pessoa com necessidades especiais. In: $9^{\circ}$ Congresso Estadual das APAEs de Minas Gerais. Anais do $9^{\circ}$ Congresso Estadual das APAEs de Minas Gerais, 9 ed. Belo Horizonte: Minas Gerais, 2004.

HANDERSON, A. The evidence continues to grow: Parent involvement improves student achievement. Columbia, MD: National Committee for Citizens in Education, 1987.

JORGE, L. Escola e Família: Um estudo da percepção de mães sobre seus filhos em inicio de escolarização. Tese de Doutorado. Universidade Estadual de Campinas, 1996.

LÓPEZ F. Problemas afetivos e de conduta na sala de aula. In: COLL, C.; MARCHESI, A.; PALACIOS, J. (Orgs.). Desenvolvimento Psicológico e Educaçáo - transtornos de desenvolvimento e necessidades educativas especiais, v. 3. Porto Alegre: Artmed, 2004. p. 113-128.

PAMPLIN, R. C. O. Dimensóes da relaçáo família-escola: programa de intervenção para professores como agentes de promoção do envolvimento parental. 2010. 212 f. Tese de Doutorado (Doutorado em Educação Especial). Programa de Pós-Graduação em Educação Especial, Universidade Federal de São Carlos, São Carlos: UFScar, 2010

A interface família-escola na inclusão da criança com necessidades educacionais especiais. 2005. 117f. Dissertação (Mestrado em Educaçâo Especial). Programa de Pós-graduaçấo em Educação Especial, Universidade Federal de São Carlos, São Carlos. 2005.

PANIAGUA P. As famílias de crianças com necessidades educativas especiais. In: COLL, C.; MARCHESI, A.; PALACIOS, J. (Orgs.). Desenvolvimento Psicológico e Educaçáo - transtornos de desenvolvimento e necessidades educativas especiais, v. 3. Porto Alegre: Artmed, 2004. p. 330-346.

PANIAGUA, P.; PALACIOS, J. Educaçáo Infantil - resposta educativa à diversidade. ed. 1. Porto Alegre: Artmed, 2007. p. 256

PANG, Y. H. Factors associated with the experiences of parents in the transitioning of their young children from early intervention to programs for three-year-olds. Dissertation Abstract International, v. 69, n. 3, p. 870, 2008.

PARO, V. H. Gestấo Democrática da Escola Pública. ed. 3. São Paulo: Editora Ática, 2001. p. 10-20

PARREIRA, V. L. C.; MARTURANO, E. M. Como ajudar seu filho na escola. São Paulo Editora Ave Maria, 1999. p. 102

PEREIRA, F. As representaçóes dos professores de educaçáo especial e as necessidades das famílias. 1996. 127f. Tese (Doutorado em Educação). Secretariado Nacional para reabilitação e integração das pessoas com deficiência, Lisboa, Portugal, 1996

PROJECT APPLESEED. Project Appleseed - The National Campaign for Public School Improvement. Washington, D.C, 2010. 
SALADINI, A. B. ; CIA, F; FANTINATO, A. C. Envolvimento paterno de pré-escolares com deficiência. In: VI Congresso Brasileiro Multidisciplinar de Educaçáo Especial. Anais VI Congresso Brasileiro Multidisciplinar de Educação Especial ano 2011. ABPEE: Londrina, 2011. p. 1249-1256.

SAMPIERI, R. H.; COLLADO, C. H.; LUCIO, P. B. Metodologia de pesquisa. 3 ed. São Paulo: McGraw -Hill, 2006. p. 583.

SMITH, B. Effects Of Home-School Collaboration And Different Forms Of Parent Involvement On Reading Achievement. 1998. 125f. Tese (Doutorado em educação) - Faculty of the Virginia Polytechnic Institute and State University. Varginia. Richmond.1998.

\section{Nota}

${ }^{1}$ Estes alunos podem estar matriculados em Centros Infantis (CI - Creches) como em Escolas de Educação Infantil (EMEI, EMEIEF, CI, e CEIEF).

\section{Correspondência}

Ana Carolina Camargo Christovam - Av. Campinas, 540. Centro, CEP: 13480-280, Limeira - São Paulo, Brasil.

E-mail: carolchristovam@hotmail.com - fabianacia@hotmail.com

Recebido em 07 de abril de 2015

Aprovado em 26 de junho de 2015 